\title{
AINDA MOFADO: UM BREVE ENSAIO SOBRE BOLOR, DE AUGUSTO ABELAIRA
}

\author{
Rodrigo Ségges Ferreira Barros ${ }^{1}$
}

\begin{abstract}
RESUMO: Escrever para entender o que se passa. A escrita como necessidade para um casal cujo silêncio da existência e da convivência conjugal representa, no microcosmo social, todo o peso político por que passa Portugal no período salazarista. Essas são as linhas teórico e ficcional com as quais Abelaira constrói o romance metaficcional Bolor. Pela falta de uso, a linguagem se embolora, põe-se, pela enunciação, entre parênteses, à espera de que as condições sociais melhorem, ou de que a leitura faça pertinente os sentidos possíveis na comunicação que só a literatura é capaz de instaurar. Por isso, o presente ensaio propõe uma leitura mais radical para um romance pouco convencional, capaz, então, de instaurar e de reforçar pela tecnologia da escrita a importância de uma resignificação da memória. Sendo assim, o limite entre ficção e realidade, a especificidade da linguagem no fazer da representação e da modernidade e os símbolos possíveis para uma escrita fora dos limites da autoria serão trazidos à baila na leitura empreendida neste ensaio. A partir de um pastiche, o referido ensaio pretende aliar o movimento de leitura realizado a algumas contribuições teóricas de Sartre, Barthes, Hutcheon, Agamben e Compagnon.
\end{abstract}

PALAVRAS-CHAVE: Bolor; limites entre ficção e realidade; a literatura portuguesa moderna.

\section{STILL MOLDY: A SHORT ESSAY ON BOLOR, AUGUSTO ABELARIA}

\begin{abstract}
Writing in order to understand what goes on. Writing as the necessity of a couple whose existent silence and relationship represent in the social microcosms all the Portuguese social retaliation faced during Salazar's Period. Those are both theoretical and fictional perspectives with which Abelaira creates the metafictional novel Bolor. Due to the lack of use, language becomes moldy, static, and consequently, shelved. Thereby, new social conditions, relevant comprehensible ways of reading through Literature, claimed at that time, would be provided. Considering the previous piece of knowledge, this paper proposes a more radical approach to an unconventional novel, and by that new reading to establish and strengthen through writing the importance of reframing memory. Thus, the boundary between fiction and reality, the specificity of language in making the representation and symbols of modernity, also the potential for writing outside the bounds of authorship will be brought to bear on the reading taken in this text. From a pastiche, that essay aims to combine some reading experiences led by theoretical contributions of Sartre, Barthes, Hutcheon, Agamben and Compagnon.
\end{abstract}

KEYWORDS: Bolor, boundaries between fiction and reality, the Modern Portuguese Literature.

\footnotetext{
${ }^{1}$ Mestrando em Teoria Literária pelo programa de pós-graduação do Departamento de Ciência da Literatura da Faculdade de Letras da UFRJ. Bolsista CNPq.
} 


\section{Sem data}

Ainda a página em branco como exemplo máximo dessa ausência, da ordem imposta de silêncio. Tudo o que pode ou poderia ser escrito, em mim, está conscientemente aceso, em alerta. Mas há essa barreira entre o que foi deixado como herança e o que de fato eu vivo com ela. Somos reduzidos a fatos da língua. Meu nome se emudece - ao ser escrito nesta folha que se tinge com minha busca por completude - num simples EU. E o nome dela num desconhecido ELA. Há um terceiro, um ELE. Todos dois sempre ausentes. Só não há um para quem se destinam minhas palavras neste caderno. Será talvez esse silêncio imposto? Nunca consegui assumir uma vida nova a cada renascimento. Como posso ser autor e leitor do que me é imposto inconscientemente daquilo que me apreende?

Tudo em estado de latência, mudos por um espião que conosco janta!

O desafio é duplo. Ao mesmo tempo em que lemos, operamos, mentalmente, a escrita de uma segunda obra. Aceito o desafio sem pestanejar, com os dedos trêmulos e com uma crescente solidão, torno, escritas, as vozes de minha leitura. Assim, como personagem não esperado, como o leite que a vaca não prometeu ${ }^{3}$, esperado apenas enquanto público maior, ensaio neste presente trabalho não só uma leitura acerca da obra de Abelaira. Ensaio também uma escrita tão possível de ser inserida nessa sua grande armadilha linguística: um diário não pautado dentro das convenções do gênero. Portanto, o trecho que abre este trabalho é a síntese do movimento tomado pela análise. Quero nas linhas que se seguem discorrer acerca do precioso labor inventivo de Abelaira ao produzir um romance caracteristicamente (pós) moderno. Esse adjetivo, como pretendo esclarecer nas linhas que ainda virão, tem como significado maior o fato de Abelaira estar inserido em um momento literário muito significativo. A produção artística deste período, para ser mais claro, a segunda fase do Neorrealismo português, tem como princípios fundamentais uma nova epistemologia quanto ao conceito de arte. Nesse momento, as obras de arte podem ser pensadas não apenas como simples produto, mas como o que as torna de fato um objeto artístico. No caso de Abelaira, que opera com palavras, quais as realizações, que movimento de escrita, serão capazes de tornar o texto escrito uma obra literária? Deste modo, classifico Bolor pós-moderno por sua (des) articulação de discurso na qual este é produzido em duas instâncias: uma referente ao plano romanesco de uma estória e outra

\footnotetext{
${ }^{2}$ Esse texto de abertura é um pastiche de um dos capítulos do romance Bolor, trabalhado por mim ao longo do presente ensaio. Como no romance de Abelaira, quis, igual a um intruso, acrescentar mais uma página no meio a tantos registros de memória e leitura. Com essa intenção, propor a abertura deste ensaio como a redação de um diário, como redação de uma das páginas que compõem o romance Bolor, é querer afirmar uma responsabilidade de "arqueologia insensata" (ABELAIRA, 1999, p. 14). Eis um objetivo para este ensaio, "eis um objetivo para este diário: observar minuciosamente as minhas relações com os outros (amigos e simples conhecidos), verificar se sim ou não os nossos diálogos gozam de propriedade comutativa, são intermutáveis, se onde está eu poderia estar indiferentemente ele”. (ABELAIRA, 1999, p. 42).

${ }^{3}$ ROSA, 2009, p. 30
} 
referente a uma produção textual que se debruça sobre si mesma. Como característica elementar, Ihab Hassan produz um trabalho crítico, The Dismemberment of Orpheus. Toward a Postmodern Literature (1982), no qual fica claro que a tradição literária pós-moderna possuiria enorme necessidade de uma escrita que desafiasse a unidade. Em outras palavras, a exigência fragmentária seria a reivindicação maior das tendências literárias desse período. Esse é um período da evolução temporal em que estaríamos todos entregues ao irreparável desmembramento das convenções literárias vigentes até então na modernidade literária. Em virtude disso, em Bolor, o romance seria capaz de verter-se sobre si mesmo para colocar em questão as tendências filosófico-literárias por que a escrita vinha passando: retração da linguagem, a ontologia movediça do autor, o estilhaçamento fracturante do sujeito, a ruína da ilusão mimética e a falência das grandes metanarrativas legitimadoras funcionam no romance de Abelaira não como uma literatura do silêncio, mas sim como resistência criativa intacta originada do caos político e filosófico por que passavam os tempos pósmodernos! No entanto, como pretendo apresentar mais à frente, essa fragmentação do romance, esse se pôr em parênteses por que opta Abelaira ao construir sua escrita, está associada não só à funcionalidade poética de uma escrita comum à pós-modernidade, mas à forma do conteúdo que essa expressão parece adquirir no enredo narrativo de Bolor. Esse romance, dado à estampa em 1968, constitui, como muitos críticos e estudiosos afirmam, uma espécie de carta de rumos da pós-modernidade literária portuguesa. Não distante de seus companheiros José Cardoso Pires, Fernando Botelho ou Urbano Tavares Rodrigues, Abelaira reforça os princípios estéticos e filosóficos que constituem a conhecida geração de 50, em Portugal.

Dentro dessa nova epistemologia, com um patente sema político caracteristicamente Neorrealista, a partir das indagações a respeito do próprio objeto literário, Abelaira trabalha com o esvaziamento da noção de indivíduo. Parece que, em seu projeto de escrita, o autor de Bolor, ao escrevê-lo, quer fazer pender a balança literária, em última consequência artística, podendo com isso, retirar a sociedade desse período de um estupor paralisante, de uma inércia intelectual e expressiva, frutos do regime político vigente. Com as contribuições de Freud, por exemplo, sabemos que só a partir da relação com o Outro podemos construir, de uma forma excêntrica, o que chamamos de consciência sobre nós mesmos. Em outras palavras, é o que pode ser chamado de "nossa individualidade". Além disso, magistralmente, esse grande escritor português vai operar com a imposição vazia expressa pelo signo linguístico, pelo silêncio com que temos de lidar quando escrevemos. A comunicação escrita, ainda mais a literária, tem de operar com um leitor em potencial, um leitor vazio, também. Com isso, o escritor assume simultaneamente dois papéis: o de emissor e o de receptor. Cada movimento de escrita tem de imaginar um movimento de leitura. É nesse jogo, num trabalho com um alterego, que a escrita de Abelaira parece se constituir. Como explicado anteriormente, além da ausência real de um interlocutor direto, uma vez que a modalidade escolhida é a escrita, Abelaira escreve num período político de silêncio, da ausência de uma recepção mais engajada, mais participante.

\footnotetext{
${ }^{4}$ Referência às distinções feitas pelo linguista Louis Hjemslev entre substancia do conteńdo (as ideias), forma do conteído (a organização dos significados), substância da expressão (os sons) e forma da expressão (a organização dos significados). (HJEMSLEV apud COMPAGNON, 2006, p. 38)
} 
Fora de uma corrente estética definida formalmente, Abelaira tem nas mãos elementos estéticos suficientes para operar com as imposições de um sistema político que por si só já impõe vazios e angústias ao sujeito: o fascismo. Vilma Arêas (1972), ao elaborar sua argumentação, explica que o fascismo é introdutor de uma desordem, de um ilogicidade, de uma arbitrariedade. É de mestre a sacada do escritor de Bolor, pois nada mais arbitrário e imposto do que o sistema linguístico a um indivíduo que se ponha a escrever, ainda mais sob condições políticas tão adversas, como a ditadura. Assim, além de um belo exemplo artístico, Bolor traz visceralmente uma discussão política patente para a época em que ocorreu o lançamento da obra, aqui, em análise. Isso se processa a partir de um jogo entre o leitor e o autor. $O$ fascismo se impõe como uma máquina feroz que não se contenta em apenas roer o futuro dos homens, mas em roê-lo a partir da deglutição de todo o seu passado. Esta é a maior imposição fascista: entendê-lo como um jogo, um jogo de acasos, de insensatez.

Tal estrutura ilógica do fascismo é tomada como elemento estruturante para o romance em discussão. Temos, diante de nós, a análise de sessenta e dois fragmentos que integram o romance. A integralização desses no tear de uma obra deixa perceber, de antemão, duas evidências. De um lado, a desigual extensão de cada fragmento: ora brevíssimos instantâneos de um parágrafo, ora distendidos excursos. Por outro lado, é evidente a sensação de que cada fragmento possui uma ordenação aleatória no corpo do romance. No entanto, predomina entre cada um desses fragmentos uma técnica combinatória sofisticadíssima. Essa técnica aproxima, pelo constante desequilíbrio sintagmático-discursivo dos fragmentos, a construção do romance a uma produção artística comum à colagem, ao patchwork. Por isso, a narrativa é um grande jogo combinatório, no qual a relação entre os narradores de cada um dos fragmentos não é dada, não é revelada $a$ priori. Além desse fato, a narrativa é obscura, cifrada. Por não ter preocupação com uma exposição direta da referência, buscando não apagar as marcas impostas pela linguagem ao apreender o real, esse romance de Abelaira tem uma linguagem opaca. É um romance que não se quer "misturar" por entre os elementos da realidade extralinguística, não se quer confundir com a crueldade dos fatos narrados. Pelo contrário, Abelaira revela, a todo instante, alertando-nos, as particularidades técnicas de sua obra. Em certa medida, durante a leitura, somos tentados a ouvir uma voz autoral que nos diria algo parecido com: "É tudo ficção, parvo leitor! Nada aqui existe, viu? É tudo o que a linguagem permite: ser puramente superfície linguística de um poço de significados que mimetizam nada mais do que o simbólico da linguagem!". Esses períodos entre aspas podem estar enunciados por Abelaira nas entrelinhas do romance. É preciso olhos atentos, então. Não há código em defesa do consumidor (leitor?) a quem possamos reclamar a falsa propaganda de um romance de diversão. Pelo contrário. É um romance cerebral, que realiza radicalmente o discurso intelectual. Tudo até aqui enunciado serve apenas como um sincero alerta. Alerta esse capaz de admitir em si mesmo que o mais confortável é chamar Bolor de uma narrativa de difícil compreensão. É o mais prudente, por ora. Ao menos, dou esse conselho a quem deseja não mais do que uma agradável e relaxante companhia de viagem pela leitura ao fim de tão desgastante dia inteiro de labuta. Será, então, necessário, mais do que depressa, deixar de lado a leitura desse romance embolorado. 
Mas todo conselho é inútil. A trama romanesca, cujo pacto de leitura - um triângulo amoroso vivido por personagens da elite - atiça nosso voyeurismo. Não há mais como escapar impune de tais avisos do autor, mesmo que, em cada linha, em cada palavra cifrada, o autor gritasse , informando-nos "Isso é ficção! Isso que você tem em mãos é artifício, não é a realidade! Isso, minha gente, é artesanal”. É impossível deixar de vender a alma à sedução exercida por Bolor. Abelaira parece encapsular, mais e mais, a linguagem representativa do que pode ser o sema capaz de denotar "o fora da língua" na própria língua. É o corpo que cria estratégias biológicas de autodefesa, como se a literatura fosse um sistema dentro do sistema linguístico materno. Em outras palavras, em muitos processos biológicos contra um ataque inflamatório, o corpo humano é capaz de inocular o ponto inflamado, criando, com estruturas fibrosas, uma barreira a fim de que o antígeno não chegue à circulação sanguínea e comprometa todo o organismo. A literatura poderia ser um corpo de defesa no corpo linguístico do idioma ao expressar uma cultura e uma sociedade doentes pelo fascismo. Tudo só se torna possível pela e na poiesis. É muito óbvia, então, a razão de, a todo o momento, ser evocado o processo de enunciação. Mais uma vez chamo atenção para a genialidade romanesca de Abelaira. A fim de não romper com a linha do enredo, para manter-nos preso ao pacto de leitura que será necessário para nos conduzir até a leitura da última linha, Abelaira busca inserir esses "alertas", disfarçando-se numa estratégia menor: os personagens do romance também escrevem, também são autores. Mas escrevem em um diário. Nada mais comum, durante a escrita desse gênero, do que realizar a evocação do seu processo de escrita - de enunciação. Além disso, ao escrever um diário, não há necessidade alguma de uma autodenominação. O diário preserva nossa identidade denotada pelos nossos nomes. Utilizando isso como recurso para disfarce quanto à evocação da enunciação, o autor de Bolor não nos permite saber quem escreve a cada trecho do diário. Há uma quebra na apresentação temporal linear e discursiva das vozes que se entrecruzam ao longo do romance. Humberto, Aleixo e Maria dos Remédios tomam indiscriminadamente o turno discursivo, a palavra, e falam e põem ainda mais dúvidas para o leitor. Ficam, na estrutura discursiva da obra em questão, as forças do sentimento sobre o ato da escrita. Quem ama, pensa e escreve. Num primeiro momento, é Humberto - espécie de narrador autodiegético. Humberto é sujeito do enunciado, obsessivamente lúcido, capaz de deambular por entre os escombros do casamento com Maria dos Remédios. O romance, em virtude disso, é uma escrita do (fim do) amor que será dado ao leitor voyeur. Esse amor exausto, dissecado, gasto e pleno do mofo de sua condição de existência é trazido, pela leitura, ao ritmo das palavras ditas ou diferidas, à medida em que o discurso consegue tomar existência pela enunciação, que, a todo momento, é evocada. Em razão disso, como já advertiu-nos Barthes, em Fragmentos de um discurso amoroso, "escrever o amor (ou, como quero forçar minha leitura, o seu fim) é enfrentar a desordem da linguagem: esta terra de loucura em que a linguagem é ao mesmo tempo muito e muito pouco, excessiva e pobre." (2001, p. 129-30). Esses dois adjetivos da fala de Barthes vão se relacionar ao perturbador impasse enunciativo comum ao romance Bolor. A redação do suposto diário íntimo de Humberto escapa do fazer discursivo desse ator comunicativo. A redação, então irá circular também por Maria dos Remédios - a esposa - e por Aleixo, amante dela. Instala-se, com isso, uma desnorteante rotatividade dos sujeitos que escrevem e/ou leem o que os outros 
escrevem. O jogo fica ainda mais denso, porque cada narrador escreve sua primeira pessoa e também na primeira pessoa do outro, numa dialética de confidência sincera e de capciosa alteridade. Ficam, então, pulverizados os limites do sujeito. Esse efeito de apagamento do sujeito do enunciado pode ser, como quero propor com minha leitura, associado ao adjetivo "excessivo", na fala de Barthes citada anteriormente. Já o adjetivo "pobre" parece representar os espaços lacunares, os poros, existentes entre os fragmentos, existentes a partir de um preenchimento discursivo dos itens dêiticos utilizados na construção da mensagem em cada suposta página de diário. Entre o excesso e a escassez, em suma, o fragmento é a tentativa perturbada - por que não perturbadora também? -, porém persistente, de fazer retumbar a voz de um coração que se descobre vazio, que se depara com o esvaziamento interpessoal trazido pela instauração do pós-moderno. Como afirma Pereira, "Bolor é, assim, uma radiografia desapiedada da mais irremissível incomunicabilidade." (2005, p. 130). Esse fato torna a narrativa porosa, ainda mais aberta. Com isso, notamos o quanto Abelaira é incrível em seu projeto de escrita, pois opera com a relação entre autor e leitor. Parece que, assim como Sartre (2004) - em Que é literatura, ao discutir, num belíssimo capítulo, a relação do autor com o fenômeno da leitura -, Abelaira sabe também que o processo criador não é senão um momento incompleto, abstrato, que um autor nunca trabalha sozinho. Tudo isso consegue, em certa medida, reforçar o papel da escrita na contemporaneidade. Concordando com as questões levantadas por Ginzburg (2011, p. 54), em Estética da morte, não há mais a realidade como um universo previamente pronto, exposto aos sentidos. O romance pós-moderno, ou a metaficção, como queiram, problematiza também os limites entre realidade e ficção. A realidade, a partir de então, está em constante interrogação, consistindo, com isso, sempre como um campo polissêmico. Logo, capaz de ser entendida de mais de um modo. Por isso, leitor, toma, em tuas mãos, essa noz dura e seca, que é a linguagem. Saiba como é difícil meu artifício, meu ofício. Quem trabalha como $\left(\mathrm{com}^{5}\right)$ eu tem que feder! ${ }^{6}$ A operação de escrever implica a de ler. Essa evocação ao ato comunicativo como um ato de coconstrução é metaforizada pelo tipo de relação existente entre os personagens narradores do romance. Esses personagens escrevem com dois propósitos muito bem definidos. Um deles é a busca do autoconhecimento. Segundo esse propósito, o signo linguístico é utilizado como uma superfície refletora. Como está expresso no trecho de 14 de Dezembro ${ }^{7}$, escrever é evocar, é trazer à tona a memória. Esses personagens, principalmente Humberto, cuja voz é mais facilmente identificável ao longo do romance - isso porque é a mais preponderante -, rememoram o passado em busca do entendimento das ações realizadas outrora. Assim, nada melhor do que as palavras escritas para evidenciar, para trazer, esse tempo passado que não está mais presente. Só a linguagem, então, é capaz de expressar na quarta dimensão do tempo, o que foi, o que é e o que pode vir. Sendo assim, a quarta dimensão

\footnotetext{
${ }^{5}$ Um trocadilho com que jogo com a ideia de companhia necessária ao fazer literário tanto durante a escrita como durante a leitura. Por isso, o dentro dos parênteses, pelo normativo do português do Brasil, tem de ser lido como "comigo".

${ }^{6}$ Alusão a um ensaio escrito por Ana Cristina Chiara, publicado em Ensaios de possessão (irrespiráveis).

7 ABELAIRA, 1999, p. 24-5.
} 
do espaço ${ }^{8}$ - que, pelo diegético, tem de ser representado na cronicidade das ações narradas do que a Crítica Literária convencionou chamar de tempo psicológico - é o signo possível. Ao reler, as memórias agora corporificadas em signos - meramente linguísticos, ou não - cada um de nós pode, com isso, chegar a um possível entendimento do que somos ou do que passamos, a uma mais clara noção do que vem a ser, de fato, esse EU. Conforme expus anteriormente, defino também a escrita por meio da perspectiva freudiana. O símbolo linguístico é um "eu" numa posição de outro. Esse símbolo é, nada mais, nada menos do que o alterego do escritor. É essa a razão de eu classificar o escrever como algo que funciona como uma superfície refletora. Ao metaforizar essa intenção, Abelaira parece pôr em tensão a relação entre autor implícito e leitor implícito. $O$ mesmo tipo de tensão fica presente quando opta por dialogar com a enunciação textual. Nesse processo de escrita, é muito provável que o escritor de Bolor esteja realizando uma ferrenha crítica às correntes artísticas que, pretensiosamente, tinham como labor estético ser a representação mimética e inequívoca, da realidade, do mundo extraliterário!

O outro propósito com que esses personagens escrevem, sobretudo principalmente as personagens Maria dos Remédios e Humberto, está associado ao fato de o diário ser, apenas por meio da leitura de trechos escritos por essas personagens, o único veículo de comunicação entre esse casal. Embora a escrita não seja endereçada diretamente, já que não fica explícita essa intenção de Humberto escrever à esposa, ele supõe que ela lerá. Mais do que isso. O diário, à medida que seguimos com a leitura de Bolor, percebemos que sofre alterações. É como se o leitor, mesmo sem permissão, lesse e respondesse, por escrito, ao que tivesse lido, inserindo, assim, uma mensagem ainda mais cifrada ao leitor do romance.

Com isso, em muitas das vezes, a escrita é utilizada, por esses personagens, como um recurso de expressão para a inabilidade quanto à comunicação oral, à interação face a face. Parece ser muito mais fácil dizer por escrito sentimentos, dar vazão a angústias e tormentos da vida cotidiana do casamento. Esse tipo de comunicação ainda simboliza o quão difícil é a vida de cônjuge, além de simbolizar também um cisma que parece existir na relação afetiva desses dois.

Portanto, nas primeiras linhas do romance, somos informados a respeito de como nossa leitura tem de operar. Tal aviso é quase indubitável: tudo só é e só é possível por intermédio da linguagem. Por essa razão, o leitor de Bolor é convidado a participar dessa coconstrução de sentidos. É preciso, todavia, deixar claro que a palavra "sentido" não entra impunemente neste ensaio, ainda mais utilizado como adjunto adnominal do termo "coconstrução". Desde Barthes (2004), o sentido não pôde mais ser entendido como instância de posse do autor. O leitor é mais do que um receptáculo. É com essa imposição teórica que o corpo do leitor terá de se manifestar no romance Bolor. Os sentidos gravitam, tais como os elétrons numa ligação covalente dativa, entre leitor e obra. No entanto, essa

\footnotetext{
${ }^{8}$ Segundo contribuições de Heidegger, o tempo e o espaço seriam categorias não mais tridimensionais, mas sim tetradimensionais. O tempo possuiria, então, as seguintes dimensões: passado, presente, futuro e LINGUAGEM. Por sua vez, o espaço seria segmentado em "comprimento", "altura", "profundidade" e "TEMPO" - na minha leitura, seria a cronicidade com que se desenrolam as ações. Isso é percebido no fato de essa dimensão do espaço só acontecer no momento em que um enunciador evoca, pela narrativa, ações já ocorridas. Seriam os flashback's comuns na narrativa. Entendo narrativa não só como item da Teoria Literária, mas como é apresentada como ferramenta pela Análise do Discurso. Cf. $A$ caminho da linguagem.
} 
nova atitude artístico-teórica imposta por Abelaira no romance em questão poderia fazer fracassar sua obra quanto à recepção, pois isso acarretaria um trabalho conceitual demais, voltado excessivamente sobre si mesmo. Para tanto, genialmente, esse escritor português parece introduzir, conforme antecipei em alguns parágrafos acima, um conflito amoroso como pacto forte de leitura. Recorrendo ao tão habitual mistério dos triângulos amorosos do romance folhetinesco, cuja estrutura supõe a cada fim de capítulo, no caso do romance em questão, a cada fim de trecho do diário, a suspensão do clímax narrativo. Isso é feito, para o caso da produção folhetinesca, com o propósito de o leitor se sentir motivado, instigado, a buscar as próximas partes, completando, deste modo, num todo, o enredo rompido. Além do tipo de trama escolhida, esse método de narrar faz com o leitor se mantenha envolvido a cada página do livro. Com isso, depois de firmado e confirmado o pacto de leitura, não há custo algum para a leitura trabalhar experimentalmente com a linguagem tal como Abelaira realiza em seu romance. Muito ciente disso, todas as lacunas, toda quebra de expectativa e todo o evocar do processo de enunciação, que, como já argumentei, faz com que o texto não se volte para uma realidade extralinguística - ou, no caso, extraliterária, já que se trata de uma obra artístico-literária - podem ser usados indiscriminadamente. O leitor não irá, - duvido muito! - de maneira alguma, recusar o projeto. Com o leitor sob seus domínios, devidamente encantado pela flauta onírica do bom narrar, Abelaira, de certa forma, realiza, portanto, seu projeto político: fazer com que, por meio desse estranhamento, dessa quebra de expectativas, o leitor reformule seus pressupostos quanto à realidade em si e quanto à recepção artística como um todo.

Contudo, esse dado clássico do romancear fica a cargo da ressignificação. Os personagens de Bolor estão em uma posição ambígua. Eles têm uma fala cerceada, silenciada, contribuindo cada vez mais para as lacunas da narrativa. Nós, leitores, como bom voyeur, sentimo-nos ainda mais presos à história. Entender o jogo que Abelaira nos propõe é também preencher os espaços que ficam, é nos posicionar diante de uma visão de casamento falido. Esse casamento é símbolo menor para uma estrutura social maior. O casamento, a todo momento, deve ser entendido como símbolo para a instauração da ordem cultural em oposição a tudo que nos é natural. Como já expus mais acima, com o casamento somos, por exemplo, forçados a um convívio com o outro de maneira mais imediata, mais intensa. Note o exagero ideológico com que enuncio o vocábulo "forçado". Isso tem uma intenção discursiva muito gritante: quero relacionar o casamento como um correlato direto das imposições fascistas. Haveria algum absurdo de análise se eu afirmar que o casamento é também um jogo do inexplicável, no qual, através da "dança" ilógica das expressões cristalizadas de um casal, por exemplo, se é obrigado a entender o desejo do Outro? Numa relação sentimental, com o tempo, é muito comum cada um dos atores da cena amorosa inferir sentidos para cada uma das atitudes tomadas pelo outro. É a isso que classifico como cristalizado, como podemos ler na passagem do romance "embora suas palavras queiram dizer não o que disseram"". É nesse movimento pela linguagem que as relações afetivas vão se coconstruindo, se reforçando, ou, no caso de Humberto e de Maria dos Remédios, vão se tornando esgarçadas, vazias semanticamente. Expressões essas

\footnotetext{
9 ABELAIRA, 1999, p. 30.
} 
repletas de uma força discursiva tamanha. Servem apenas no âmbito do pragmático, pois pouco têm a ver com um referente dentro do espaço diegético com que se constrói o mundo extralinguístico onde se insere o casal. Esse vazio de sentidos está bem claro na relação entre os personagens e na passagem do texto em que Maria dos Remédios reclama da distância de Humberto, como fica claro no capítulo do livro intitulado como 22 de Dez̧embro. Nesse mesmo fragmento, chamo a atenção para a correlação entre casamento e fascismo no fato de o próprio narrador desse possível trecho de diário entender que só com o novo podemos despertar para o outro. O novo é sempre o estímulo. Seja um novo amante, seja um novo sistema político!

Talvez esse seja o maior trunfo para assumir a leitura de Bolor em sua relação com a realidade vivida por Portugal na época do fascismo político. As normas e os valores do leitor, conforme defende Compagnon (2001), devem ser modificados pela experiência com a leitura. Quando lemos, evocamos, por meio da expectativa, sentidos comuns às práticas anteriores de leitura. No entanto, para que uma leitura venha contribuir com uma suposta reformulação de nossa realidade, é preciso que nos deparemos com um dado não familiar. Desta forma, a contribuição de Abelaira em discutir o fascismo é inovadora por duas razões. A primeira deve ser atribuída ao fato de esse trabalho do autor manter estreito vínculo com as considerações a respeito da relação participativa entre autor e leitor, comum às letras a partir das vanguardas do início do século XX. Esse é o grande estranhamento com o qual o leitor precisa lidar. As normas e a lógica para os elementos linguísticos utilizados na construção da mensagem literária de Bolor são semelhantes às regras que estruturam a sociedade portuguesa no período fascista. Há, em outras palavras, uma posição silenciada e mediada por um simbólico no qual se exige uma participação ativa, coconstrutora de significados. Isso fica claro no fato de haver comunicação entre o casal do romance apenas através da invasão de leitura, ou, como mesmo está escrito no trecho de 22 de Dezembro, "as palavras cruzadas entre nós". A escrita do romance se potencializa como símbolo máximo do silêncio, do espaço sonoro emudecido, calado à força de muitas circunstâncias. Ainda nesse trecho, há uma outra passagem que denota a ressignificação da escrita para o preenchimento de silêncios, desses vazios: "a tentativa de encher os momentos em que sou obrigado a estar sozinho". Esse parece ser o grande objetivo do diário. Numa escala maior, esse seria o grande objetivo da escrita como um todo. Em virtude disso, a linguagem, além de ajudar o enunciador a se entender a si mesmo, é o único veículo entre um casal de "uma casa gasta, com nenhum estímulo". São como dois estranhos sob o mesmo teto. O que era para ser a busca de uma felicidade comum, tornouse, ao longo do tempo, um abismo. Esse casal está "entregue a coisas diferentes", como poeticamente deixa falar pelo silêncio das palavras escritas a passagem do capítulo 22 de Dez̧embro, presente em Bolor. Isso parece conotar o espaço sonoro silenciado entre eles como símbolo para a fala interna de um que escreve e que, ao mesmo tempo, é capaz de se ler, e de um que lê e que se deixa escrever. Mais uma vez, entremeado ao enredo, Abelaira vai construindo sua reflexão acerca da potencialidade da linguagem literária à medida que narra, com tamanha poesia, o cotidiano falido de uma relação conjugal.

A segunda razão para o fato de Bolor ser compreendido nesta leitura como inovador se associa a presente operacionalização empreendida na escrita do romance com conceitos 
muito comuns ao tipo literário narrativo. $O$ romance abelariano opera com a elisão da subjetividade e do tempo. Quanto à subjetividade, Abelaira trabalha como pronomes pessoais de uma forma a mascarar a pessoalidade de seus referentes. Isso é ainda mais paradoxal; mas, ao mesmo tempo, muito lógico, pois o espaço físico em que transcorrem as narrativas admite a manutenção desse segredo. Ao escrever em um diário, ninguém tem a obrigação de declarar o próprio nome, mantendo-o, em virtude dessa intenção enunciativa, escondido atrás dos usos de pronomes e referências textuais com essas marcas de pessoa a verdadeira identidade. Portanto, com tal argumento, almejo deixar claro o quanto a escrita de Bolor quer chamar atenção para os processos enunciativos de sua produção. Parece haver uma alerta ao leitor para o livro que se tem em mãos. Esse alerta reverberaria, pela atualização da leitura, nas tramas ficcionais de uma mimesis de representação. Abelaira deveria gritar, ou escrever no rodapé de cada página de seu romance, tal como Magritte ${ }^{10}$ : "É um livro, não a realidade!" Nem seria demais reforçar que essa realidade era a preocupação-mestra da tradição realista, cuja pretensão era apresentar-se como a correspondência unívoca entre os entes da realidade e a representação discursiva, literária. No entanto, as inovações tecnológicas e as contribuições artístico-filosóficas do começo do século XX estarão na contramão dessa postura ingênua da representação realista. Toda expressão discursiva se constrói com elementos simbólicos postos no lugar daquilo que não está mais ali. Não se pode registrar o instante, apenas a impressão que se tem dele de acordo com o momento no qual podemos percebê-lo. Fica, portanto, dessa impressão, na estrutura discursiva de representação, apenas o traço, os resquícios da memória, o signo, os pontos e toda força da enunciação. A realidade, no entanto, escapa-nos mais uma vez das mãos.

Essa relação da arte com a realidade é ainda problematizada na escrita de Bolor pela suspensão temporal. O tempo predominante no romance é o presente. No entanto, é um presente angustiado, esvaziado em sua relação com o passado e com o futuro. Esse esvaziamento pode ser lido como a própria situação política em que vivia Portugal. Não é à toa que o título do romance é "bolor". Bolor é uma forma assumida pelos fungos diante de condições inóspitas de existência, como a falta de água e de alimentos. Para que não se perca por completo o "patrimônio de vida", esses fungos assumem essa forma a fim de economizarem energia até que as condições do ambiente voltem a ser favoráveis. Essa minha leitura é corroborada num trecho do romance de Abelaira: "deviam emudecer, pôrse entre parênteses até que o mundo se transforme" (1999, p. 49). A enunciação literária em um romance foram os parênteses por que Abelaira optou: tomar a forma de mofo, de bolor, servindo como um meio simbólico de alerta acerca de sua realidade política imediata. Portanto, mesmo em tratar do tempo, embora fosse um futuro tomado pelas lentes de um passado, em que é rememorado, nada melhor que o presente para significar o estado de sítio em que vivem os personagens do romance. Essa condição é o espelho maior das condições políticas por que passou Abelaira: o fascismo. Além disso, é preciso salientar o fato de que, no gênero escolhido para o romance, esse tipo de tempo verbal é logicamente

10 Referência ao quadro do surrealista belga René Magritte, no qual, ao representar figurativamente um cachimbo, o artista insere a inscrição abaixo da figura: "Ceci n’est pas une pipe." (Isso não é um cachimbo tradução minha). 
aceito. O diário nada mais é do que a representificação de uma memória, de um dado do passado. Esse também é mais um dos pactos de leitura firmado pelo leitor com Bolor.

Que maneira outra haveria para terminar as discussões que fui levantando ao longo deste ensaio, senão deixar que a escrita silencie tudo à míngua da suspensão! $\mathrm{Na}$ escrita, a linguagem se faz possível na impossibilidade de significação do tempo, da identidade e da existência. Tudo em mim, a partir do que não tem mais, por ora, vida, do que não tem mais potência no presente, pede expressão. Falta-me apenas linguagem! A via de acesso, então, seria também colocar qualquer tentativa de palavra final entre os parênteses do que foi e do que um dia possa se tornar a ser. O presente não é mais o agora. O presente é a ficcionalização da leitura ao escrever com mãos alheias às de Abelaira o que a poesia desse maravilhoso escritor português contemporâneo faz mofar em Bolor. Foi o que tentei, foi o que a língua minha me permitiu expressar. Tudo transitório, tudo fugidio...

\section{BIBLIOGRAFIA}

ABELAIRA, Augusto. Bolor: (romance). Rio de Janeiro: Lacerda Editora, 1999.

AGAMBEN, Giorgio. "O Autor como gesto.” In: Profanações. Tradução de Selvino J. Assmann. Lisboa: Edições Cotovia, 2005, p. 83-101.

ARÊAS, Vilma. A cicatriz e o verbo: análise da obra romanesca de Augusto Abelaira. Rio de Janeiro: Casa da Medalha, 1972.

BARTHES, Roland. Fragmentos de um discurso amoroso. Lisboa: edições 70, 2001. . "A morte do autor". In: O rumor da língua. Tradução de Mário Laranjeira. São Paulo: Martins Fontes, 2004, p. 57-75.

CHIARA, Ana Cristina. "Quem trabalha como eu tem que feder. In: Ensaios de possessão (irrespiráveis). Rio de Janeiro: Caetés, 2006, p. 35-44.

COMPAGNON, Antoine. "A literatura"; "O leitor". In: O demônio da teoria: literatura e senso comum. Tradução de Cleonice Paes Barreto Mourão e Consuelo Fortes Santiago. Belo Horizonte: UFMG Editora, 2001, cap. I e V, p. 29-46; p. $139-164$.

GINZBURG, Jaime. "Estética da morte". In: Gragoatá: Publicação dos Programas de PósGraduação do Instituto de Letras da Universidade Federal Fluminense. ISSN 1413-9073. Niterói-RJ: EdUFF, n. 31, 2. sem. 2011, p.51-61.

HASSAN, Ihab. The Dismemberment of Orpheus. Toward a Postmodern Literature. Madison: The University of Wisconsin Press, 1982.

HEIDEGGER, Martin. A caminho da linguagem. Tradução de Marcia Sá Cavalcante Schuback. Petrópolis, RJ: Vozes, 2003.

HUTCHEON, Linda. "Metaficção historiográfica: 'o passatempo do tempo passado". In: Poética do pós-modernismo: história, teoria e ficção. Tradução de Ricardo Cruz. Rio de Janeiro: Imago Editora, 1991, cap. 7, p. 141-162.

PEREIRA, Paulo Alexandre. "Como quem enfia as pedras de um colar": diário e fragmentação em Bolor, de Augusto Abelaira. In: Revista Forma Breve. Aveiro: Centro de 
Línguas e Culturas da Universidade de Aveiro, 2005. p. 125-139. Disponível em http://www2.dlc.ua.pt/classicos/Abelaira.pdf, acesso em 25/05/2012.

ROSA, Guimarães. "Aletria e hermenêutica”. In: . Tutameia (terceiras estórias). Rio de Janeiro: Ediouro Publicações, 2009, p. 29-40.

SARTRE, Jean-Paul. "Que é escrever?". In: Que é a literatura? Tradução Carlos Felipe Moisés. São Paulo: Ática, 2004, p. 9-32.

Artigo recebido em 29 de Março de 2013.

Artigo aprovado em 03 de Dezembro de 2013. 